\title{
OPEN Publisher Correction: Signal transmission through elements of the cytoskeleton form an optimized information network in eukaryotic cells
}

\section{B. R. Frieden ${ }^{1} \&$ R. A. Gatenby ${ }^{2}$}

Correction to: Scientific Reports https://doi.org/10.1038/s41598-019-42343-2, published online 16 April 2019

This Article contains errors.

In the section called 'Its Physical Manifestation J, EPI Principle',

"The principle (3) of Extreme Physical Information or EPI has been used to derive most of textbook physics ${ }^{46}$ and some laws of biology ${ }^{54}$ including a prediction of power law growth $m(t)=m(0) t^{\dagger O}$ for early-growth stages of breast cancer ${ }^{52,55}$ where the constant $\backslash \mathrm{O}=1.618034$ that has been confirmed in multiple studies using mammography data."

should read:

"The principle (3) of Extreme Physical Information or EPI has been used to derive most of textbook physics ${ }^{46}$ and some laws of biology ${ }^{54}$ including a prediction of power law growth $m(t)=m(0) t^{\phi}$ for early-growth stages of breast cancer ${ }^{52,55}$ where the constant $\phi=1.618034$ is the Fibonacci golden mean, widely observed in biological growth processes including multiple studies of mammographic cancer data."

In addition, in the section called 'Transition to Principle of Minimum Kullback-Leibler (KL) Divergence',

“Then probability $p_{i}(t)$ after entering the cytoplasm a short time $\Delta t$ later is $p_{i}(t+t)$."

should read:

“Then probability is $p_{i}(t)$ after entering the cytoplasm a short time $\Delta t$ later is $p_{i}(t+\Delta t)$.

Finally, Reference 45 which was incorrectly given as:

Frieden, B. R. \& Frieden, B. R. Science from Fisher information: a unification. 2nd edn, (Cambridge University Press, 2004).

The correct reference is written below as Reference 1 :

\section{Reference}

1. Frieden, B. R. Science from Fisher information: a unification. 2nd edn, (Cambridge University Press, 2004).

${ }^{1}$ College of Optical Science, University of Arizona, Tucson, AZ, USA. ${ }^{2}$ Department of Integrated Mathematical Biology, Moffitt Cancer Center, Tampa, FL, USA. Correspondence and requests for materials should be addressed to R.A.G. (email: Robert.Gatenby@moffitt.org) 
(c) (i) Open Access This article is licensed under a Creative Commons Attribution 4.0 International License, which permits use, sharing, adaptation, distribution and reproduction in any medium or format, as long as you give appropriate credit to the original author(s) and the source, provide a link to the Creative Commons license, and indicate if changes were made. The images or other third party material in this article are included in the article's Creative Commons license, unless indicated otherwise in a credit line to the material. If material is not included in the article's Creative Commons license and your intended use is not permitted by statutory regulation or exceeds the permitted use, you will need to obtain permission directly from the copyright holder. To view a copy of this license, visit http://creativecommons.org/licenses/by/4.0/.

(C) The Author(s) 2019 